Mateja Prinčič

\title{
Ernst Spaan, Felicitas Hillmann, Ton van Naerssen (ur.): Asian Migrants and European Labour Markets. Patterns and processes of immigrant labour market insertion in Europe
}

London, New York: Routledge, 2005, 2012, 337 strani

Maja 2001 je v nizozemskem mestu Nijmegen potekala konferenca na temo Azijski podjetniki in priseljenci v Evropski skupnosti, v okviru katere se je odvil prvi delovni seminar, ki je osredinil vlogo azijskih priseljencev in njihovih podjetniških strategij znotraj evropskega delovnega trga. Rezultati konference so bili leta 2005 združeni v monografiji European Labour Markets ter konec leta 2012 v ponatisu izdani pri založbi Routledge.

Delo sestavlja petnajst prispevkov petindvajsetih avtorjev, v veliki meri geografov in drugih strokovnjakov s področja priseljenske problematike in zaposlovanja. Predstavljeni so rezultati raziskav, izvedenih v devetih evropskih državah, in v nekaterih primerih tudi rezultati terenskega dela v izvornih državah priseljencev. Prostorsko so prispevki osredotočeni na priseljence iz Južne, Jugovzhodne in Vzhodne Azije, časovno pa na devetdeseta leta 20 . stoletja, ko so se zgodile pomembne strukturne spremembe v vzorcih in modelih zaposlovanja tako znotraj Evrope kot tudi širše v razvitem svetu.

Če se najprej ustavimo znotraj historičnega konteksta kolonialnih struktur Velike Britanije, Francije in Nizozemske, so kasnejše preference azijskih migracijskih tokov v smeri teh evropskih držav dokaj samoumevne. Vendar pa so to zgolj opaznejši, tradicionalni migracijski prostori. Da bi se izognili posplošitvam, so $\mathrm{v}$ prispevkih predstavljeni tudi bolj neobičajni primeri, kot so na primer sikhovski molzci krav na lombardskem podeželju. Avtorji v svojih člankih tako ne upoštevajo zgolj globalnih, marveč tudi lokalne in regionalne razvojne komponente ter njihove medsebojne povezave, ki so v diskurzu globalizacije še toliko lažje spregledane. Globalizacija je korenito posegla $\mathrm{v}$ strukturo evropskega delovnega trga in privedla do povečanih potreb po fleksibilni delovni sili ter porastu neuradnih oblik zaposlovanja. Od osemdesetih let 20. stoletja dalje so se začeli odvijati procesi privatizacije, deregulacije in zmanjševanja državnih intervencij $\mathrm{v}$ gospodarstvu. Uspešne preureditve trga 
zaposlovanja v neoliberalnem duhu znotraj Evropske unije bi bile tako težko izvedljive, če ne bi povečanih potreb po nizkokvalificirani in prilagodljivejši delovni sili zapolnili priseljenci. Hkrati so devetdeseta leta prinesla spremembe tudi na področju migracijske politike znotraj Evropske unije. Po eni strani so se omejitve priseljevanja za sočlane znotraj Evropske unije zmanjšale, po drugi pa so se za nečlane izven unije poostrile. S tovrstno realnostjo so se soočili posamezniki in skupine azijskih priseljencev, predstavljeni v knjigi. V primerjavi z azijskimi priseljenci, ki so v Evropo prišli v sedemdesetih in osemdesetih letih 20. stoletja, so bili priseljenci v devetdesetih letih postavljeni v še bolj zapleten socialno-ekonomski položaj.

$\mathrm{V}$ delu velja izpostaviti tri pomembnejše in najpogostejše vidike preučevanja azijskih priseljencev v odnosu do podjetniških in zaposlovalnih praks. Prvi vidik je vezan na t. i. koncept transnacionalizma, katerega sestavni del so transnacionalna družinska omrežja in transnacionalne prakse evropsko-azijskih socialnih, ekonomskih in kulturnih omrežij. V tovrstnih družbenih omrežjih je zgoščen velik delež človeškega in socialnega kapitala, ki se ga poslužujejo tako azijski priseljenci kot tudi evropski delodajalci. Tovrsten pristop med drugim tudi problematizira tradicionalne vidike integracije priseljencev. Drugi vidik je vezan na t. i. koncept mešane vpetosti, ki so ga leta $1999 \mathrm{v}$ članku Mixed Embeddedness: (In)formal Economic Activities and Immigrant Businesses in the Netherlands časopisa International Journal of Urban and Regional Research po Polanyijevem prvotnem konceptu vpetosti reinterpretirali Robert Kloosterman, Joanne van der Leun in Jan Rath. Po mnenju teh treh avtorjev je bistvo t. i. mešane vpetosti $v$ tem, »da je vzpon imigrantskega podjetništva primarno lociran na presečišču socialno-kulturnih okvirov na eni strani ter sprememb znotraj (urbanih) ekonomij in institucionalnih okvirov na drugi strani«. Tretji vidik pa je vezan na področje sociologije spolov in ženskega zaposlovanja znotraj priseljenskih skupin, zlasti na študijah primerov filipinskih žensk kot hišnih pomočnic in medicinskih sester.

Metodološko gledano so se avtorji pri svojih raziskavah oprli delno na kvantitativne, zlasti pa zaradi narave dela na kvalitativne raziskave, v veliki meri izvedene s pomočjo terenskega dela in polstrukturiranih intervjujev. V vsebino dela so vključeni posamični izseki nekaterih intervjujev, statistične razpredelnice z relevantnimi statističnimi spremenljivkami, z geografskega gledišča pa pade $\mathrm{v}$ oči zlasti odsotnost kartografskih prikazov prostorske razpršenosti pojavov in procesov. Omejena zanesljivost in dostopnost kvantitativnih podatkov zaradi nezabeleženih nezakonitih priseljencev $\mathrm{v}$ uradnih statistikah ter nacionalne razlike pri definicijah etničnega sestava priseljencev so botrovale dejstvu, da primerjave med posameznimi državami večinoma niso bile predstavljene. 
Petnajst različnih prispevkov je razdeljenih na tri obsežnejša poglavja. V prvem poglavju, poimenovanem Znotraj sistema, so članki, povezani z azijskimi priseljenci, ki so že utečeni "znotraj sistema«. Raziskave so usmerjene v obseg in stopnjo socialno-ekonomske vključenosti znotraj držav prihoda. Drugo poglavje, Vstopanje, obravnava strategije, ki se jih poslužujejo priseljenci za vstop na evropski trg dela, in težave, s katerimi se soočajo ob vstopu. Tretje in zadnje poglavje ima več kot zgovoren naslov - Samozaposlitev in podjetništvo med azijskimi priseljenci v Evropi. Ključne, najzanimivejše sinteze ugotovitev večine avtorjev so podane v nadaljevanju.

V prvem poglavju Giles A. Barrett in David McEvoy problematizirata položaj azijskih priseljencev na britanskem zaposlitvenem tržišču. Kot ugotavljata, večja fleksibilnost zaposlitvenega trga v Veliki Britaniji ni prinesla bolje plačanih zaposlitvenih možnosti za azijske priseljence. Ti se bolje izkazujejo v samozaposlitveni vlogi, ki pa je v veliki meri odraz pomanjkanja alternativnih ekonomskih priložnosti. Christiane Hintermann in Ursula Reeger prikažeta samoiniciativne ter uspešne poteze indijskih in filipinskih medicinskih sester kot hiter odziv na potrebe po kvalificiranem kadru $\mathrm{v}$ dunajskih bolnišnicah v sedemdesetih letih 20. stoletja. Poleg te institucionalizirane oblike zaposlitvene integracije pa po drugi strani pokažeta na neuspešnost integracije indijskih pouličnih prodajalcev časopisov na Dunaju. Felicitas Hillmann primerjalno predstavi dva migracijska sistema, segajoča $\mathrm{v}$ čas blokovske delitve, na primeru Vietnamcev v Berlinu. V Zahodnem Berlinu je bila skupnost Vietnamcev, povečini političnih priseljencev, uspešno integrirana s pomočjo in konsenzom zahodnonemške družbe. Na drugi strani zavese v Vzhodnem Berlinu pa je bila usoda Vietnamcev povsem drugačna. Njihov prihod v Nemško demokratično republiko je bil vezan na sklop bilateralnih pogodb med tema dvema socialističnima republikama, s katerimi je NDR ekonomsko pomagala Vietnamu. Prihod Vietnamcev je bil vezan na delo v večjih industrijskih obratih NDR, kjer kakršnakoli integracija sploh ni bila zaželena. Po padcu Berlinskega zidu so se številni Vietnamci iz vzhodnega dela Berlina znašli v kočljivem položaju zaradi nespretnosti lastne integracije. Socialnih vezi med skupnostjo v Zahodnem in Vzhodnem Berlinu pa zlasti zaradi političnih razhajanj skorajda ni bilo. Krystina Iglicka prav tako poudari pomen družbene tolerantnosti za dobro počutje in integracijo Vietnamcev na Poljskem od sedemdesetih let dalje.

V drugem poglavju Maria Josè Compiani in Fabio Quassoli na podlagi treh osnovnih modelov zaposlitvene integracije priseljencev v Italiji, povzetih po Mauriziu Ambrosiniju, predstavljata stanje v devetdesetih letih v Italiji. Poleg metropolitanskega, industrijskega ter sezonskega oziroma podeželskega modela predstavita povsem specifičen primer sikhovskih molzcev krav v Lombardiji. Bergamini, kot jih imenujejo lokalni prebivalci, so primer ambicioznega migracijskega projekta indijskih Sikhov, ki imajo znotraj svoje dejavnosti povsem monopolen položaj. Velika prednost tovrstnega 
dela je v dejstvu, da zaposlovalci Sikhom priskrbijo brezplačno nastanitev s plačanimi računi ter nadpovprečne plače, Sikhi pa zaposlovalcem veliko mero fleksibilnosti in zavzetosti. Natalia Ribas - Mateos in Laura Oso predstavita študijo primera filipinskih hišnih pomočnic v Španiji kot primer netipične in nepodjetniške azijske strategije. Prav tako so filipinske pomočnice v ospredju naslednjega prispevka. Liane Mozère hišne pomočnice v Parizu v primerjavi s prejšnjima avtoricama vidi kot »podjetnice samih sebe« na transnacionalnem zaposlitvenem tržišču. So izobražene, angleško govoreče, mediatorke med dvema svetovoma, opremljene s t. i. migracijskimi kompetencami in poznane pod hudomušnim imenom »Mercedes-Benz med hišnimi pomočnicami«. Kot pravijo zadnje tri avtorice, so v izvorni državi cenjene in dojete kot subjekti, ki v skupnost vnašajo modernizacijo, so glavne akterke skupnega družinskega migracijskega projekta. Njihova transnacionalna kariera se skozi intervjuje na primer kaže v ambicioznih željah po izgradnji manjše klinike ali hotela na Filipinih.

Monder Ram in Trevor Jones $\mathrm{v}$ tretjem poglavju na podlagi pridobljenih polstrukturiranih intervjujev poudarjata, da v podjetništvu že uveljavljeni azijski priseljenci v Veliki Britaniji pri pridobivanju novega kadra ne iščejo prednostno pripadnikov iste etnične skupnosti. S tem opozorita na potrebo po preseganju zgolj kulturalističnih vidikov poslovnih dinamik. Ernst Spaan, Ton van Naerssen in Harry van den Tillaart na podlagi študije primera, vezane na prebivalce nekdanjih Molukov, ovržejo vsestranski sloves azijskih priseljencev kot zelo aktivnih članov na evropskem zaposlitvenem trgu. Kljub nizozemskim državnim podporam za integracijo na delovnem tržišču so v podjetništvu zelo slabo zastopani, saj naj bi bile solidarnost, recipročnost in pomoč znotraj skupnosti pomembnejše vrednote kot poslovni duh. Daniele Cologna v članku o kitajskih podjetnikih v Milanu v nasprotju z uveljavljenim mnenjem o močnih solidarnostnih vezeh znotraj kitajske skupnosti poudarja še vedno močno prisotnost družinskih vezi, ne pa več tudi etničnih. Maggi Leung podobno kot že nekateri predhodni avtorji na podlagi študij primerov geografskih značilnosti omrežij na lokalni, regionalni in transnacionalni ravni preseže vidike kulturnega determinizma, ki določajo poslovne strategije.

Obravnavani zbornik izpostavlja in zmanjšuje raziskovalno vrzel na področju večplastne azijsko-evropske migracijske problematike devetdesetih let 20 . stoletja in kliče po novih raziskavah $\mathrm{v}$ trenutnih, spreminjajočih se globalnih ekonomskih razmerah. 